\title{
PLANTAS INVASORAS PARA MELHORAR A EFICIÊNCIA DA CALAGEM NA CORREÇÃO DA ACIDEZ SUBSUPERFICIAL DO SOLO(1)
}

\author{
A. R. MEDA ${ }^{(2)}$, M. A. PAVAN ${ }^{(3)}$, M. MIYAZAWA $^{(3)}$ \& M. E. CASSIOLATO ${ }^{(4)}$
}

\begin{abstract}
RESUMO
Foram desenvolvidos estudos com colunas de solo $(\varnothing=4 \mathrm{~cm} ; \mathrm{h}=25 \mathrm{~cm}) \mathrm{em}$ condições de laboratório, em Londri na, durante os anos de 1999 e 2000, uti lizandose o horizonte Bw de um Latossolo Vermelho. As seguintes plantas foram testadas: agriãozinho das pastagens (Synedrel lopsis grisebachi i ), carrapicho-decarneiro (Acanthospermum hispidum), caruru roxo (Amaranthus hybridus), cordão-de-frade (Leonotis nepetifolia), losna branca (Parthenium hysterophorus), mamona (Ricinus communis), picão branco (Galinsoga parvifl ora) e trapoeraba (Commelina benghalensis). Extratos aquosos da parte aérea das plantas (3 g em $150 \mathrm{~mL}$ ) foram aplicados na superfície do solo e lixiviados com três volumes de poros de água destilada, em tratamentos com calcário na superfície. Avaliaramse as alterações no pH do solo e os teores de cátions trocáveis ( $\mathrm{Ca}, \mathrm{Al}, \mathrm{K}$ e Mg) em camadas do solo de $5 \mathrm{~cm}$ e na solução efluente. A calagem superficial (sem extrato vegetal) aumentou o pH e o Ca e diminuiu o Al apenas no local de aplicação e, em menor intensidade, na camada de $5-10 \mathrm{~cm}$. Os extratos de plantas e calagem superficial aumentaram o pH e reduziram Al até $20 \mathrm{~cm}$ de profundidade. A mamona foi a planta invasora que apresentou a maior capacidade de transportar $\mathrm{Ca}$, elevando a concentração do nutriente até $15 \mathrm{~cm}$ de profundidade. As plantas de maior efeito na acidez foram: picão branco e trapoeraba, que também causaram a maior lixiviação de Al da coluna de solo. As de menor efeito foram: agriãozinho e carrapicho-de-carneiro. As plantas invasoras testadas apresentaram potencial para uso, objetivando o aumento da eficiência da calagem na correção da acidez da subsuperfície do solo.
\end{abstract}

Termos de indexação: complexação organometálica, resíduos vegetais, mobilização de Ca.

(1) Extraído do Trabalho de Conclusão do Curso de Graduação (TCC), apresentado pelo primeiro autor ao Departamento de Agronomia da Universidade Estadual de Londrina - UEL, para obtenção do Grau de Engenheiro-Agrônomo. Recebido para publicação em março de 2001 e aprovado em abril de 2002.

(2) Engenheiro-Agrônomo, Pós-Graduando em Biologia Vegetal, Universidade Estadual de Campinas - UNICAMP. Rua Belo Horizonte 940, CEP 86020-902 Londrina (PR). E-mail: meda@uol.com.br

(3) Pesquisador do Instituto Agronômico do Paraná - IAPAR. Caixa Postal 481, CEP 86001-970 Londrina (PR). E-mail: miyazawa@pr.gov.br

(4) Engenheiro-Agrônomo, Pós-Graduando em Solos e Nutrição de Plantas, Escola Superior de Agricultura "Luiz de Queiroz" ESALQ/USP. Av. Domingos Perino 477, CEP 19900-000 Ourinhos (SP). E-mail: mecassiolato@uol.com.br 


\title{
SUMMARY: WEED EXTRACTS TO IMPROVE EFFICIENCY OF LIME AS SUBSOIL ACIDITY NEUTRALIZER
}

\begin{abstract}
Studies with soil col umns $(\varnothing=4 \mathrm{~cm} ; \mathrm{h}=25 \mathrm{~cm})$ were carried out under laboratory conditions in theyears 1999 and 2000, in Londrina, using theBw horizon of a Red Latosol . The following weed species were tested: Synedrellopsis grisebachii, Acanthospermum hispidum, Amaranthus hybridus, Leonotis nepetifolia, Parthenium hysterophorus, Ricinus communis, Galinsoga parviflora and Commelina benghalensis. Shoot extracts ( $3 \mathrm{~g}$ in $150 \mathrm{~mL}$ of water) were applied onto the soil surface with a lime top dressing and then leached with threeporevolumes of deionized water. Alterations of soil pH and exchangeable cation contents were determined, taking samples from soil layers of $5 \mathrm{~cm}$ and leached solutions from the columns. Liming without plant extracts increased soil pH and $\mathrm{Ca}$ and decreased $\mathrm{Al}$ in the top layer, and, less intense, in the $5-10 \mathrm{~cm}$ layer. Liming with plant extracts increased soil pH and reduced Al down to $20 \mathrm{~cm}$ of depth. Ricinus communis presented thegreatest capacity as Ca carrier, increasing its content down to $15 \mathrm{~cm}$ of depth. G. parviflora and C. benghalensis reduced soil acidity most effectivel y and al so stimulated highest Al leaching, while least effective weeds wereS. grisebachii and A. hispidum. The tested plant extracts present potential to transfer limeal kal inity to acid soil subsurface.
\end{abstract}

Index terms: plant residues, metal-organic complex, Ca leaching.

\section{NTRODUÇÃO}

Grandes áreas do território brasileiro são de sol os ácidos que apresentam deficiência generalizada de bases trocáveis ( $\mathrm{Ca}, \mathrm{Mg}, \mathrm{K}$ ), níveis tóxicos deAl, baixa capacidade de troca de cátions e baixos teores de matéria orgânica. Essas condições restringem o desenvolvimento radicular das plantas e, conseqüentemente, diminuem sua capacidade em absorver água e nutrientes, a não ser que sejam adotadas práticas corretivas (Olmos \& Camargo, 1975).

A calagem é a prática tradicional que visa, principalmente, ao aumento de $\mathrm{pH}, \mathrm{Ca}$ e $\mathrm{Mg}$, à neutralização do Al tóxico e ao aumento da CTC efetiva (Pavan \& Oliveira, 1997). A restrição quanto a essa prática é que o efeito do cal cário somente se limita à sua profundidade deaplicação no sol o (Pavan et al., 1984; Hue\& Licudine, 1999) e, por isso, quando aplicado na superfície, as condições do subsol o podem permanecer adversas ao crescimento radicular.

Para estender os efeitos da calagem em profundidade, basicamente, três práticas podem ser utilizadas: a incorporação motomecanizada (GonzalezErico et al., 1979), a mobilização quími co-inorgânica (Shainberg et al., 1989) e a mobilização químicoorgânica (Miyazawa et al., 2000).

A incorporação motomecanizada do calcário é possível somente em sistemas convencionais de cultivo, sendo impraticável em sistemas de plantio direto e para culturas perenes estabel ecidas. Além disso, pode ser onerosa e muitas vezes indesejável, em virtude da exposição de subsolo infértil (Liu \& Hue, 1996).
Por outrolado, a mobilização químico-inorgânica constitui-se no uso de sais inorgânicos de $\mathrm{Ca}$, como - gesso agrícola, que, aliado à calagem superficial , aumenta os teores de Ca e diminui a toxidez de Al em profundidade (Pavan et al., 1984). Todavia, o uso do gesso podecausar lixiviação de cátions básicos, além de não provocar aumentos no pH do solo, queé um fator fundamental para disponibilização de cargas negativas nos sítios de troca dos colóides do solo (Hue \& Licudine, 1999).

A mobilização químico-orgânica da frentealcalina do cal cário foi recentemente observada em sistema de plantio direto (Oliveira \& Pavan, 1996) e em pomar de macieiras estabelecidas manejado com resíduos de aveia preta e plantas invasoras (Pavan, 1994), onde a calagem superficial causou redução de Al e aumentos de $\mathrm{pH}$ e Ca até $40 \mathrm{~cm}$ de profundidade. Resultados de experimentos em condições de laboratório comprovam que a mobilização químico-orgânica da frente al calina do calcário aplicado superficialmente é devida à liberação de compostos orgâni cos hidrossolúveis, de baixo peso molecular, pelos resíduos vegetais presentes na superfície do solo, antes do início da decomposição microbiana (F ranchini et al ., 1999a,b). Esses compostos orgânicos apresentam capacidade de complexar e mobilizar Ca (Ziglio et al., 1999; Franchini et al., 2001), el evar opH (Noble\& Randall, 1998) e neutralizar oAl em profundidade (Pohlman \& McColl, 1988).

Considerando o el evado potencial de produção de biomassa das plantas invasoras nos sistemas agrícolas brasileiros (Favero et al., 2000) e, conseqüentemente, o alto potencial de liberação de compostos orgânicos no sol o, há interesse em utilizar 
essas plantas para mel horar a eficiência da calagem na correção da acidez subsuperficial do solo. Em vista desta possibilidade, foram desenvolvidos experimentos de laboratório, objetivando avaliar a capacidade das plantas invasoras na mobilização da frente al calina da calagem superficial.

\section{MATERIAL E MÉTODOS}

O experimento foi desenvolvido nolaboratório de solos da estação experimental doI nstitutoAgronômico do Paraná (IAPAR), em Londrina.

Amostras do horizonte Bw de um Latossolo Vermelho foram coletadas em área não cultivada, na região de Arapongas (PR). Esse horizonte foi escolhido por apresentar maior acidez e menor teor de matéria orgânica. O solo foi preparado secandoseao ar, moído e passado em peneira de $2 \mathrm{~mm}$, sendo caracterizado quimicamente de acordo com Pavan et al. (1992) e fisicamente de acordo com o método da EMBRAPA (1997) (Quadro 1).

Amostra do sol o original foi incubada com $\mathrm{CaCO}_{3}$ P.A. em dose para neutralização de $100 \%$ da acidez total $(\mathrm{H}+\mathrm{Al})$, por um período de três meses. Após, analisou-se o solo (Quadro 1).

Amostras da parte aérea de espécies de plantas invasoras em estádio de florescimento foram col hidas em áreas agrícolas do estado do Paraná, no segundo semestre de 1999 eprimeirosemestre de2000. Foram testadas as seguintes espécies: agriãozinho das pastagens (Synedrellopsis grisebachii), carrapicho-decarneiro (Acanthospermum hispidum), caruru roxo (Amaranthus hybridus), cordão-de-frade (Leonotis nepetifolia), losna branca (Partheni um hysterophorus), mamona (Ricinus communis), picão branco (Galinsoga parviflora) e trapoeraba (Commelina benghalensis). O material vegetal foi seco em estufa com ventilação forçada a $65{ }^{\circ} \mathrm{C}$, moído em triturador para forrageiras e armazenado em saco plástico. A composição química de cada material vegetal, determinada segundo método de Miyazawa et al. (1992b), encontra-se no quadro 2.

\section{Quadro 2. Composição química dos materiais vegetais}

\begin{tabular}{|c|c|c|c|c|c|}
\hline Material vegetal & $\mathbf{N}$ & $\mathbf{P}$ & $\mathbf{K}$ & $\mathrm{Ca}$ & Mg \\
\hline & \multicolumn{5}{|c|}{$\mathrm{g} \mathrm{kg}^{-1}$} \\
\hline Agriãozinho & 24 & 3 & 24 & 24 & 8 \\
\hline Carrapicho-de-carneiro & 22 & 4 & 25 & 13 & 6 \\
\hline Caruru roxo & 38 & 6 & 33 & 30 & 11 \\
\hline Cordão-de-frade & 25 & 3 & 23 & 19 & $\begin{array}{r}1+ \\
6\end{array}$ \\
\hline Losna branca & 22 & 3 & 30 & 12 & 4 \\
\hline Mamona & 31 & 3 & 15 & 26 & 6 \\
\hline Picão branco & 36 & 7 & 33 & 23 & 5 \\
\hline Trapoeraba & 30 & 4 & 39 & 21 & 7 \\
\hline
\end{tabular}

Foi obti do extrato do material vegetal, visando à solubilização de compostos hidrossolúveis pelo seguinte procedimento: foram pesados $3 \mathrm{~g}$ do material seco e moído (equivalentes a aproximadamente $10 \mathrm{Mg} \mathrm{ha}^{-1}$, calculados de acordo com a quantidade de sol o esperada em 1 ha, em $20 \mathrm{~cm}$ de profundidade, com densi dade aparente de $1,16 \mathrm{~g} \mathrm{~cm}^{-3}$ ), adicionados $150 \mathrm{~mL}$ de água destilada (equivalentes a 1 volume de poros do sol o em estudo, determinados conforme Pavan et al., 1984), em um frasco de vidro de $300 \mathrm{~mL}$. O material foi agitado a $175 \mathrm{rpm}$ por quatro horas e filtrado em al godão sintético. U ma subamostra do extrato foi utilizada para determinações de $\mathrm{pH}$ e teores de Ca, Mg eK (Quadro 3).

Os tratamentos foram: testemunha (sem cal cário, sem extrato vegetal), cal cário (sem extrato vegetal) e cal cário + extrato vegetal (com cada uma das oito espécies testadas individualmente), perfazendo, ao todo, dez tratamentos. O delineamento foi de blocos inteiramente casualizados, em três repetições. Os tratamentos com cal cário consistiram na utilização do sol o incubado com $\mathrm{CaCO}_{3}$ P.A. (Quadro 1) colocado no topo da col una de PVC, sendo equival entea uma calagem de $4 \mathrm{Mg} \mathrm{ha}^{-1}$.

Subamostra de solo foi transferida para uma coluna de PVC $(\varnothing=4 \mathrm{~cm} ; \mathrm{h}=25 \mathrm{~cm})$, revestida

Quadro 1. Composição física e química do solo original e incubado com $\mathrm{CaCO}_{3}$

\begin{tabular}{|c|c|c|c|c|c|c|c|c|c|c|}
\hline Solo & Argila & Silte & Areia & $\mathbf{C}$ & $\mathrm{pH} \mathrm{CaCl} 2$ & Al & $\mathbf{H}+\mathbf{A l}$ & $\mathbf{C a}$ & Mg & $\mathbf{K}$ \\
\hline & \multicolumn{4}{|c|}{$\mathrm{g} \mathrm{kg}^{-1}$} & & \multicolumn{5}{|c|}{$-\mathrm{cmol}_{\mathrm{c}} \mathrm{dm}^{-3}$} \\
\hline Original & 280 & 30 & 690 & 9,23 & 4,1 & 1,10 & 6,20 & 0,43 & 0,19 & 0,06 \\
\hline Incubado & $* *$ & $* *$ & $* *$ & 9,11 & 7,5 & 0,00 & 1,75 & 5,28 & 0,13 & 0,05 \\
\hline
\end{tabular}

** Não determinado. 
internamente com saco plástico e compactada para obtenção de uma densidade aparente homogênea (média de 1,16 $\mathrm{g} \mathrm{cm}^{-3}$ ), correspondendo à condição natural. Para otratamento com cal cário, preencheuse a coluna com solo original na profundidade 5$25 \mathrm{~cm}$, compl etando-se o restante com sol o cor rigido.

I mediatamente após sua obtenção, o extrato vegetal $(150 \mathrm{~mL})$ foi aplicado na superfície do solo contido na coluna, com gotejadores. A seguir, adicionou-se água destilada no total de $450 \mathrm{~mL}$, quantidade equivalente a três volumes de poros. $\mathrm{O}$ extrato ea água destilada foram aplicados com uma vazão de aproximadamente $1,7 \mathrm{~mL} \mathrm{~min}^{-1}$.

A cada volume de poros adicionado ( $150 \mathrm{~mL}$ ) coletou-se a solução efluente, totalizando três amostras por coluna. A seguir, foram determinados $\mathrm{Ca}, \mathrm{Mg}, \mathrm{Al}$ (por espectrofotometria de absorção atômica induzida por plasma) e K (por fotometria de chama). I mediatamente após o término da percolação do terceiro volume de poros, o solo foi amostrado em camadas de 0-5, 5-10, 10-15, 15-20 e 20-25 cm de profundidade, seco ao ar, moído, passado em peneira de $2 \mathrm{~mm}$ e analisado quimicamente, de acordo com Pavan et al. (1992).

A avaliação dos efeitos da calagem superficial e extratos vegetais nas propriedades químicas do solo e solução percolada foi realizada pela análise de variância, e as médias, comparadas pelo Teste de Tukey a $5 \%$.

\section{RESULTADOS E DISCUSSÃO}

Os extratos de material vegetal apresentaram grande variação na sua composição química (Quadro 3). O extrato de picão branco apresentou a maior concentração de Ca; mamona e caruru roxo, as maiores de Mg e esse último também a maior de $\mathrm{K}$, assim como a trapoeraba. O extrato de picão branco também apresentou a maior concentração de cátions básicos $(\Sigma \mathrm{Ca}+\mathrm{Mg}+\mathrm{K})$, e carrapicho-de-carneiro, a menor concentração. Os valores de pH variaram de levementeácido a levementeal calino, tendo o extrato de mamona apresentado o maior $\mathrm{pH}$, enquanto carrapicho-de-carneiro, losna branca e trapoeraba, os menores valores.

Em relação ao teor de nutriente na planta (Quadro 2) e no extrato (Quadro 3), de forma geral, observou-se que a solubilidade dos íons diminui na ordem $\mathrm{K}>\mathrm{Mg}>\mathrm{Ca}$. Essa seqüência pode ser explicada pela função e mobilidade que esses el ementos apresentam nas plantas (Malavol ta et al., 1997). O K mostra alta mobilidade no floema e não forma complexos estáveis com ânions. O Mg, assim como oK, apresenta mobilidade no floema, mas pode estar associado a ânions pouco solúveis em água. $\mathrm{O}$ $\mathrm{Ca}$, por sua vez, apresenta pouca mobilidade no floema e exerce papel fundamental na estruturação de membranas e paredes celulares, estando fortemente ligado a esses componentes, de baixa solubilidade em água.

Percebeu-se, porém, uma variabilidade entre as espécies quanto à solubilidade de $\mathrm{Mg}$ e $\mathrm{Ca}$. Praticamente todo o $\mathrm{K}$ presente no tecido foi solubilizado no extrato (média $92 \%$ ), com baixa variabilidade entre as espécies. No entanto, Mg apresentou uma solubilidade média de $35 \%$ eCa de 24 \%. Esse último apresentou uma maior variação em relação aos demais, pois houve solubilização de $63 \%$ do Ca presente no tecido de picão branco e apenas $0,5 \%$ no tecido de caruru roxo.

Para cada propriedade química do solo, houve efeito diferenciado entre os materiais vegetais testados. A fim de facilitar a visualização dos resultados, passa-se a demonstrar o efeito de três materiais representativos, sendo o primeiro o de maior efeito; o segundo, de efeito intermediário, e o terceiro, de menor efeito. Os valores da primeira camada $(0-5 \mathrm{~cm})$ foram omiti dos em decorrência da pouca al teração das propriedades químicas causada pelos extratos vegetais nessa camada e maior interesse de enfatizar o efeito dos extratos vegetais na subsuperfície do solo.

Quadro 3. Composição química dos extratos vegetais

\begin{tabular}{|c|c|c|c|c|c|}
\hline Extrato vegetal & $\mathbf{p H}$ & $\mathrm{Ca}$ & Mg & $\mathbf{K}$ & $\sum \mathrm{Ca}+\mathrm{Mg}+\mathrm{K}$ \\
\hline & & \multicolumn{4}{|c|}{$-\mathrm{mmol}_{\mathrm{c}} \mathrm{L}^{-1}$} \\
\hline Agriãozinho & 6,7 & 2,79 & 3,38 & 12,10 & 18,27 \\
\hline Carrapicho-de-carneiro & 5,8 & 1,50 & 2,88 & 10,87 & 15,25 \\
\hline Caruru roxo & 6,3 & 0,15 & 5,41 & 16,79 & 22,35 \\
\hline Cordão-de-frade & 6,2 & 5,34 & 2,26 & 10,87 & 18,47 \\
\hline Losna branca & 5,8 & 1,76 & 2,46 & 15,51 & 19,73 \\
\hline Mamona & 7,4 & 7,51 & 5,40 & 6,77 & 19,68 \\
\hline Picão branco & 6,5 & 14,44 & 3,64 & 14,23 & 32,31 \\
\hline Trapoeraba & 5,8 & 7,09 & 4,06 & 16,79 & 27,94 \\
\hline
\end{tabular}


O solo da testemunha caracterizou-se pela alta acidez (Figura 1 ) e elevado teor de Al trocável (Figura 2) e baixos teores de cátions básicos (Figuras 3, 4 e 5). O efeito do tratamento somente com calagem superficial no aumento do $\mathrm{pH}$ do solo foi restrito à camada de $5-10 \mathrm{~cm}$, porém, nãosignificativo. Nas demais profundidades, o efeito do calcário foi nulo, condizendo com resultados amplamente documentados na literatura (Pavan et al., 1984; Bó, 1985; Ziglio et al., 1999). No entanto, nos tratamentos com extratos de plantas ecalagem, o $\mathrm{pH}$ aumentou até $20 \mathrm{~cm}$ de profundidade. Os extratos de picão branco etrapoeraba foram os mais eficientes para o aumento de $\mathrm{pH}$; em seguida, caruru roxo, mamona e losna branca e, finalmente, os extratos de carrapicho-de-carneiro, agriãozinho e cordão-de-frade.

$\mathrm{O}$ efeito somente da calagem no aumento de $\mathrm{Ca}$ no solo (Figura 3) foi restrito à camada de $5-10 \mathrm{~cm}$, provavel mente pelo consumo do $\mathrm{OH}^{-}$liberado pela reação do cal cário com os componentes áci dos do solo, deixando o Ca desacompanhado e adsorvido à superfície de troca dos colóides do solo. O princípio da neutralidade indica queo movimento de Ca deve ser acompanhado por ânions equivalentes. Dessa forma, a movimentação de Ca não seria esperada quando o calcário fosse aplicado isoladamente na superfície, a não ser em doses el evadas. Liu \& Hue (1996) verificaram, em experimento com sais de Ca, em coluna de solo, que apenas $2 \%$ do total do $\mathrm{Ca}$ adicionado na forma de $\mathrm{CaCO}_{3}$ moveu-se além de $15 \mathrm{~cm}$ de profundidade, comparado a $68 \%$ do $\mathrm{CaCl}_{2}$ e $35-75 \%$ de Ca-fulvato.

Os tratamentos com extratos e calagem aumentaram Ca nas camadas de 5-10 cm, com exceção do caruru roxo, que provocou uma pequena redução desse elemento nessa camada. O extrato demamona aumentou Ca até $15 \mathrm{~cm}$ de profundidade, apresentando-se como a espécie vegetal mais promissora para possibilitar o transporte de $\mathrm{Ca}$ em profundidade. $\mathrm{Na}$ camada de $20-25 \mathrm{~cm}$, não ocorreram alterações significativas nos teores de Ca em todos os tratamentos com extrato das plantas em relação à testemunha e calagem superficial sem extrato (Figura 3).

A calagem sem aplicação de extrato vegetal apresentou efeito no teor deAl trocável somente na camada de $5-10 \mathrm{~cm}$ (Figura 2), reduzindo o teor original de $0,92 \mathrm{cmol}_{\mathrm{c}} \mathrm{dm}^{-3}$ (testemunha) para $0,68 \mathrm{cmol}_{\mathrm{C}} \mathrm{dm}^{-3}$, sem, no entanto, causar efeito nas demais profundidades. Os tratamentos com extratos de plantas e calagem apresentaram al ta capacidade de reduzir Al até $20 \mathrm{~cm}$ de profundi dade, destacandose trapoeraba e picão branco. Observou-se pequeno efeito dessas espécies na camada de $20-25 \mathrm{~cm}$, porém sem diferença significativa em relação à testemunha e calagem superficial sem extrato.

De acordo com Hue \& Licudine (1999), as moléculas orgânicas presentes nos extratos vegetais, como complexos de $\mathrm{Ca}$, facilitariam o movimento vertical de $\mathrm{Ca}$. Aolongo dessemovimento reagiriam

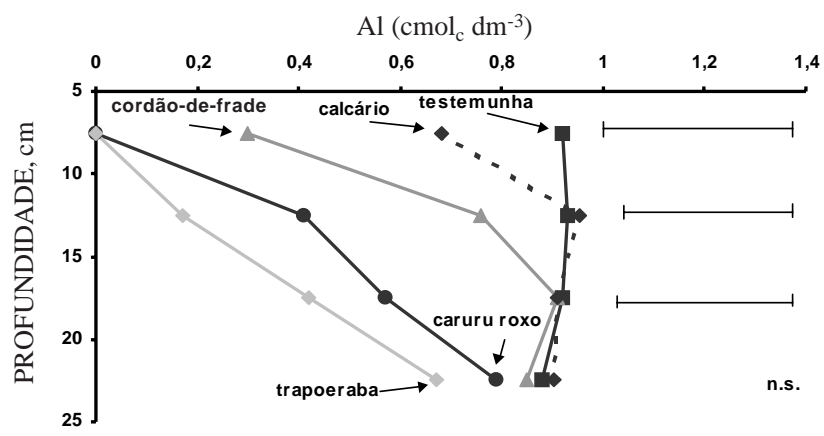

Figura 2. E feito dos extratos de plantas com cal cário e de calagem superficial nos teores de Al no solo, em diferentes profundidades. Barras horizontais representam a diferença mínima significativa indicada pelo teste de Tukey $(P<0,05)$.

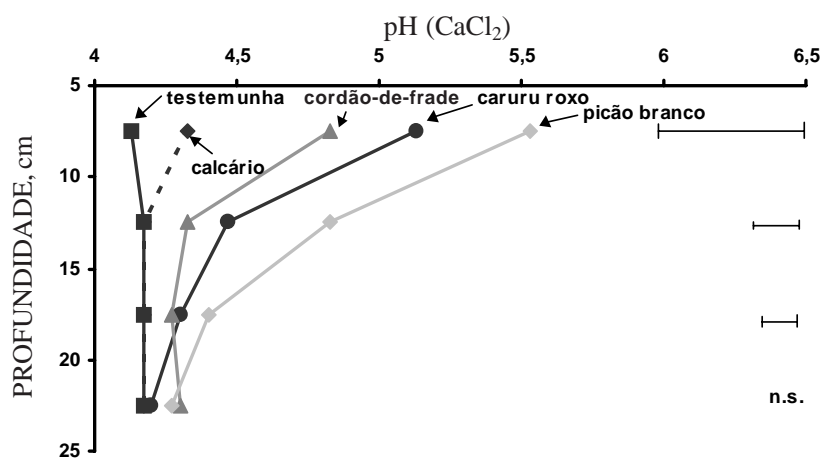

Figura 1. Efeito dos extratos de plantas com calcário e de calagem superficial no pH do solo, em diferentes profundidades. Barras horizontais representam a diferença mínima significativa indicada pelo teste de Tukey $(P<0,05)$.

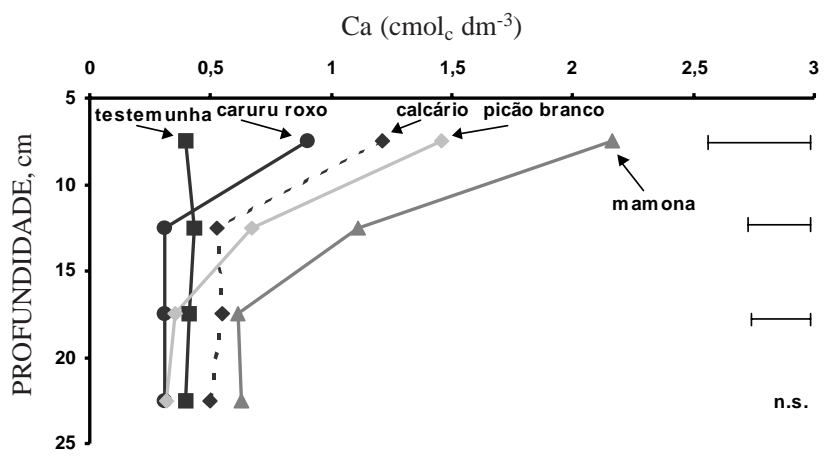

Figura 3. E feito dos extratos de plantas com cal cário e de calagem superficial nos teores de Ca no solo, em diferentes profundidades. Barras horizontais representam a diferença mínima significativa indicada pelo teste de Tukey $(P<0,05)$. 
com Al, formando compl exos eliberando o Ca que se tornaria disponível às plantas. Além disso, consistente com o aumento de pH, a concentração deAl da superfície detroca diminuiu, provavel mente, mediante a precipitação doAl-solução $\operatorname{comoAl}(\mathrm{OH})_{3}$. Esses dois mecanismos parecem estar envolvidos na redução do Al do complexo de troca. Franchini et al. (1999a) evidenciaram, na separação do Al-total da sol ução do sol o em sua forma orgânica emonomérica, em solo incubado com resíduos vegetais, que acima de 90 \% do Al em solução estava na forma orgânica, demonstrando a participação dos compostos orgânicos na redução de Al trocável do solo.

Pohlman \& McColl (1988) verificaram queácidos orgânicos livres com alta capacidade de complexação, aromáticos (ex: gálico, protocatecóico, hidroxibenzóico, vanídico, benzóico) e alifáticos (ex: oxálico, maléico, aconítico, fumárico, málico) representavam 60-80 \% dos ácidos orgânicos livres em extratos deserrapilheira florestal, obtendo correlação significativa entre áci do orgâni co livreeAl dissolvidona solução do solo.

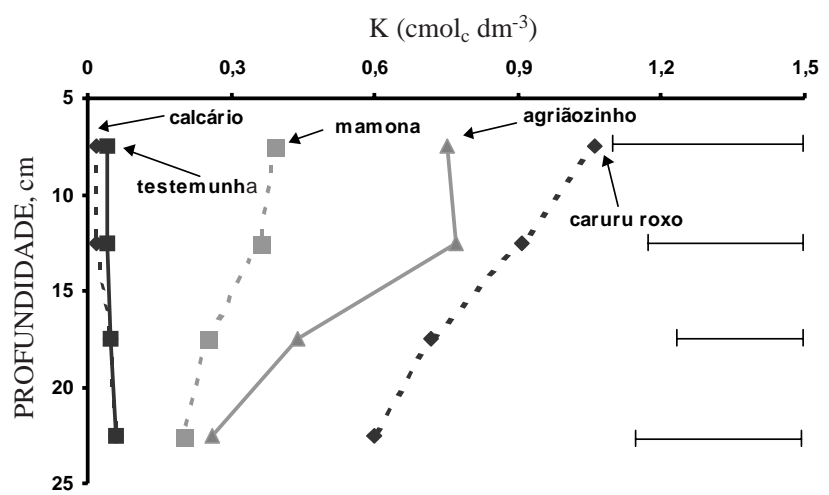

Figura 4. Efeito dos extratos de plantas com calcário e de calagem superficial nos teores de $K$ no solo, em diferentes profundidades. Barras horizontais representam a diferença mínima significativa indicada pelo teste de Tukey $(P<0,05)$.

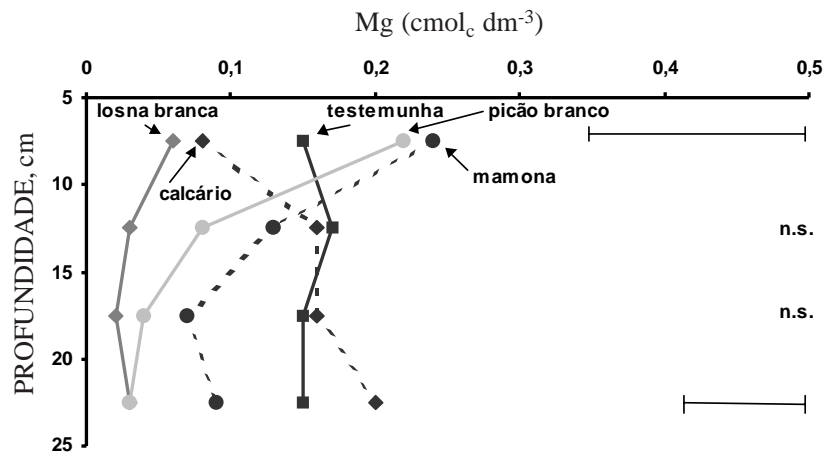

Figura 5. Efeito dos extratos de plantas com cal cário e de calagem superficial nos teores de Mg no solo, em diferentes profundidades. Barras horizontais representam a diferença mínima significativa indicada pelo teste de Tukey $(P<0,05)$.
Franchini et al. (2001) demonstraram que, em extratos de tremoço azul e nabo forrageiro, com alta capacidade de formação de complexos estáveis com Al, os ácidos orgâni cos de cadeia curta apresentavamse em alta proporção entre os compostos orgânicos presentes (20 e $30 \%$ respectivamente). Miyazawa et al. (1992a) comprovaram que os complexos Alácido orgânico foram menos tóxicos para as raízes de trigo do que as formas iônicas de Al. Portanto, acredita-se que, em solo manejado com plantas invasoras, a calagem superficial reduza a fitotoxidez do Al em profundidade, possibilitando o maior desenvolvimento das raízes das plantas cultivadas.

$\mathrm{Na}$ figura 4, pode ser observado o efeito dos extratos das plantas invasoras nos teores de $\mathrm{K}$ trocável. Os extratos proporcionaram grande acúmul o do el emento em todo o perfil do solo; os que proporcionaram os mai ores aumentos foram caruru roxo, Iosna branca, picão branco e trapoeraba. O extrato de mamona causou o menor aumento de $\mathrm{K}$ no perfil do solo, ainda assim, muito superior à testemunha e calcário superficial sem extrato vegetal. Esse resultado tem sido comum nesse tipo de estudo, em que se observa um aumento significativo de $\mathrm{K}$ trocável em solo ácido lixiviado com extratos de plantas (Meda et al., 1999).

Loyola J r. \& Pavan (1989), entre outros, demonstraram que a força de adsorção dos cátions pelos colóides do solo diminui na ordem: $\mathrm{Ca}^{2+}>\mathrm{Mg}^{2+}>\mathrm{K}^{+}$. Esses autores ainda documentaram que a menor afinidade do $\mathrm{K}+$ pel os solos do Paraná pode ser devida à provável ausência de minerais de argila com maior capacidade de adsorção de K. A lixiviação preferencial de $\mathrm{Ca}$ em relação ao K, portanto, é um indicativo da formação de complexos orgânicos com Ca. Na forma complexada, o Ca teria sua carga líquida alterada para carga nula ou negativa, sendo preferencialmente lixiviado em relação aoK diante da carga líquida negativa do sol o (Franchini et al., 1999b). O sololixiviado com extrato de mamona apresentou a maior concentração de Ca e menor de K, enquanto para o caruru roxo ocorreu o inverso. Dessa forma, pode-se destacar o papel dos compostos orgâni cos em competirem com os sítios de adsorção dos cátions na superfície de troca dos colói des do solo. Em sistemas inorgânicos, seria esperada a lixiviação preferencial do K, com o Ca predominando nos sítios de troca do solo.

Os extratos de plantas causaram uma diminuição de $\mathrm{Mg}$ nas profundidades de $10-25 \mathrm{~cm}$ (Figura 5), com $\mathrm{K}$ e $\mathrm{Ca}$ dominando o complexo de troca, que provavelmente resultou da combinação dos seguintes efeitos (Liu \& Hue, 1996): (1) competição Ca-Mg, (2) complexação do $\mathrm{Mg}$ por compostos hidrossolúveis e conseqüentelixiviação para solução efluente e (3) competição do íon de menor afinidade (K) pelo complexo de troca, porém mais abundante nos extratos. Esse último efeito é suportado pelo fato de terem ocorrido grandes aumentos de $\mathrm{K}$ 
trocável nos tratamentos lixiviados com os extratos vegetais (Figura 4). Provavelmente, se o corretivo utilizado contivesse $\mathrm{Mg}$ em sua composição, a diminuição desse elemento no solo poderia ser minimizada.

A lixiviação total de íons da coluna de solo pode ser observada na figura 6 , que contém o total lixiviado de $\mathrm{Ca}, \mathrm{Al}, \mathrm{K}$ e Mg. Os extratos de plantas proporcionaram um grande aumento da lixiviação deCa (Figura 6a). A calagem superficial sem extrato, por sua vez, não aumentou o teor de Ca na solução, indicando a sua baixa mobilidade na ausência de ânions acompanhantes, nesse caso, dos ligantes orgânicos. Soprano \& Alvarez (1989) apresentaram resultados semelhantes em um experimento de lixiviação de nutrientes de colunas de solo com sais deCa, verificando a baixa lixiviação de Ca da coluna quando utilizado $\mathrm{CaCO}_{3}$.

A presença de Al foi praticamente nula nos tratamentos: testemunha e calagem sem extrato (Figura 6b). Na presença dos extratos, a quantidade de Al lixiviado da coluna foi elevada, tendo os extratos de trapoeraba e picão branco apresentado os maiores aumentos desse el emento na solução percolada, enquanto os extratos de agriãozinho, caruru roxo e carrapicho-de-carneiro, os menores aumentos. Esses aumentos são consistentes com a diminuição deAl trocável do solo (Figura 2), em que os extratos detrapoeraba epicão branco foram os mais efetivos. Isso permiteadmitir quehouve complexação organometálica, pois, seguindo a substituição do Al peloK eCa no complexo de troca, os íons deslocados, provavelmente, foram lixiviados para as maiores profundidades ou removidos do sistema, aumentando a concentração de Al na solução efluente.

Os tratamentos com extratos causaram grandes aumentos de K na solução efluente em relação à testemunha e calagem superficial sem extrato (Figura 6c), sendo reflexo da el evada concentração desse elemento nos extratos. O extrato de picão branco causou a maior lixiviação de K, enquanto os extratos de cordão-de-frade, agriãozinho, mamona e carrapicho-de-carneiro causaram menor efeito.

Os extratos aumentaram a lixiviação de $\mathrm{Mg}$, sendo agriãozinho o mais efetivo e cordão-de-frade o menos efetivo; ainda assim, superior à testemunha e calagem superficial sem extrato (Figura $6 \mathrm{~d}$ ).

A lixiviação de cátions na solução efluente evidencia não só uma al teração na dinâmica dosíons em solo ácido manejado com plantas invasoras, caracterizando um sistema de manejo orgânico do solo, mas também a capacidade de mobilização da frente alcalina da calagem superficial por essas espécies.
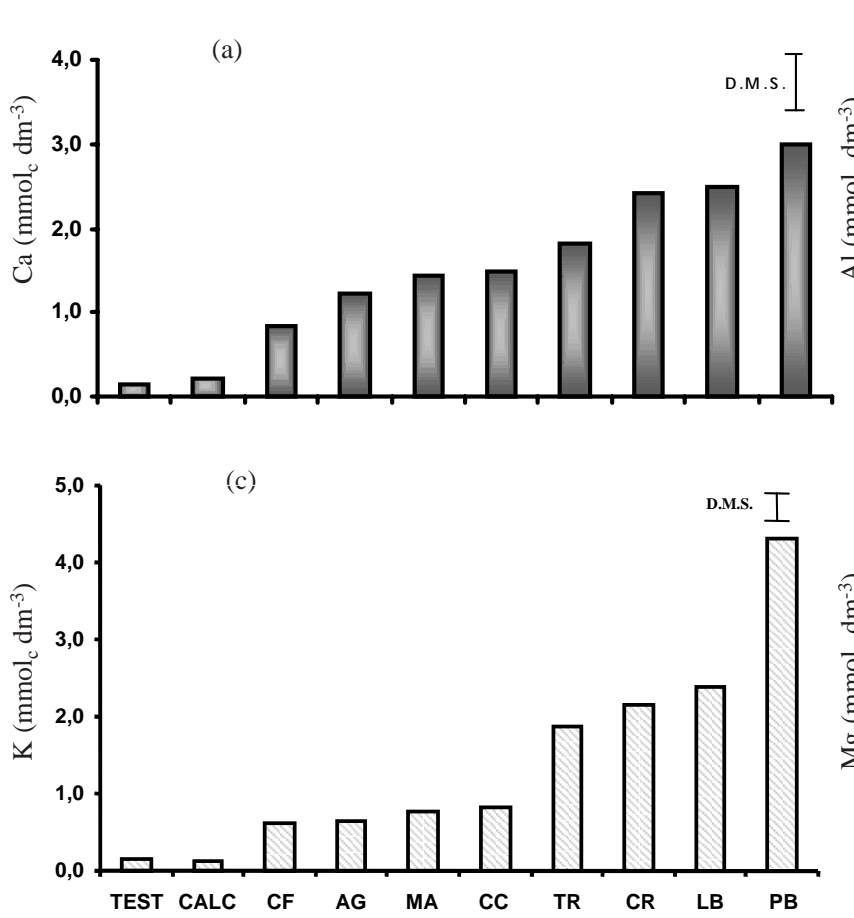

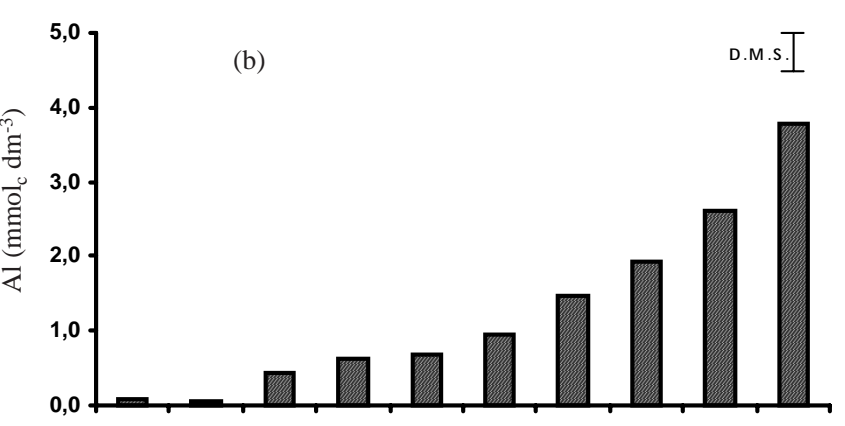

(d)

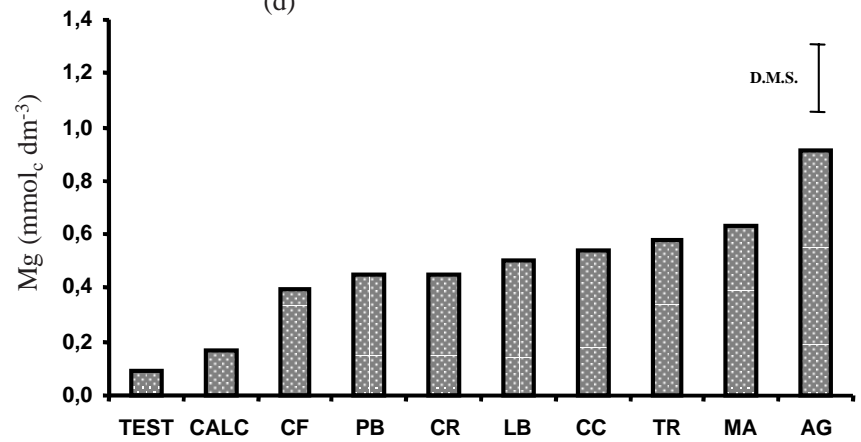

TEST = testemunha, CALC = calcário, AG = agriãozinho, CC = carrapicho-de-carneiro, CR = caruru roxo, $\mathrm{CF}=$ cordão-de-frade, $\mathrm{LB}=$ losna branca, $\mathrm{MA}=$ mamona, $\mathrm{PB}=$ picão branco e TR = trapoeraba.

Figura 6. Efeito dos extratos vegetais na composi ção química da solução efluente da coluna de solo [cálcio (a), alumínio (b), potássio (c) e magnésio (d)]. Barras verticais representam a diferença mínima significativa indicada pelo teste de Tukey $(P<0,05)$. 


\section{CONCLUSÃO}

1. As plantas invasoras apresentam potencial para serem manejadas em solos ácidos, visando à mobilização da frente alcalina da calagem superficial, possibilitando a extensão dos seus efeitos para a subsuperfície do solo.

\section{AGRADECIMENTOS}

Anderson R. Meda e Marcelo E. Cassiolato agradecem a Maria de Fátima $M$. Bloch e à equipe do laboratório de solos do IAPAR, pelo auxílio nos experimentos; ao IAPAR/PIBIC/CNPq, pela concessão da bol sa deiniciação científica. O primeiro autor agradece ao Prof. Dr. Pedro R. F urlani, pelo auxílio nas análises estatísticas.

\section{LITE RATURA CITADA}

BÓ, M.A.D. Movimentação de bases e crescimento de raízes de cana-de-açúcar em colunas de solo, em função da adição de diferentes sais de cálcio. Viçosa, Universidade Federal de Viçosa, 1985. 62p. (Tese de Mestrado)

EMPRESA BRASILEIRA DE PESQUISA AGROPECUÁRIA EMBRAPA. Centro Nacional de Pesquisa de Solos. Manual de métodos de análise de solo. 2.ed. Rio de J aneiro, 1997. p.27-34. (EMBRAPA-CNPS Documentos, 1)

FAVERO, C.; J UCKSCH, I.; COSTA, L.M.; ALVARENGA, R.C. \& NEVES, J.C.L. Crescimento e acúmulo de nutrientes por plantas espontâneas e por leguminosas utilizadas para adubação verde. R. Bras. Ci. Solo, 24:171-177, 2000.

FRANCHINI,J .C.; MALAVOLTA,.E.; MIYAZAWA, M. \& PAVAN, M.A. Alterações químicas em solos ácidos após a aplicação deresíduos vegetais. R. Bras. Ci. Solo, 23:533-542, 1999a.

FRANCHINI,J.C.; MIYAZAWA, M.;PAVAN, M.A. \& MALAVOLTA, E. Dinâmica de íons em solo ácido lixiviado com extratos de resíduos de adubos verdes e soluções puras de ácidos orgânicos. Pesq. Agropec. Bras., 34:2267-2276, 1999b.

FRANCHINI, J.C.; GONZALEZ-VILA, F.J .; CABRERA, F.; MIYAZAWA, M. \& PAVAN, M.A. Rapid transformations of plant water-soluble organic compounds in relation to cation mobilization in an acid Oxisol. Plant Soil, 231:55-63, 2001.

GONZALEZ-ERICO, E.; KAMPRATH, E.J .; NADERMAN, G.C. $\&$ SOARES, W.V. Effects of deep lime incorporation on the growth of corn on an Oxisol of central Brazil. Soil Sci. Soc. Am. J., 43:1155-1158, 1979.

HUE, N.V. \& LICUDINE, D.L. Ameliorating of subsoil acidity through surface application of organic manures. J. Environ. Qual., 28:623-632, 1999.

LIU, J. \& HUE, N.V. Ameliorating subsoil acidity by surface application of calcium fulvates derived from common organic materials. Bio. Fertil. Soils, 21:264-270, 1996.

LOYOLA J r., E. \& PAVAN, M.A. Seletividade de troca de cátions em solos ácidos. R. Bras. Ci. Solo, 13:131-138, 1989.
MALAVOLTA, E.; VITTI, G.C. \& OLIVEIRA, S.A. Avaliação do estado nutricional das plantas: princípios e aplicações. 2 ed. Piracicaba, POTAFOS, 1997. 319p.

MEDA, A.R.; CASSIOLATO, M.E.; MIYAZAWA, M. \& PAVAN, M.A. Plant extracts to improve acid soil chemistry. In: CONGRESO LATINOAMERICANO DE LA CIENCIA DEL SUELO, 14., Pucon, 1999. Anais. Temuco, Universidade de la Fronteira, 1999. p.360.

MIYAZAWA, M.; CHIERICE, G.O. \& PAVAN, M.A. Amenização da toxicidade de alumínio às raízes de trigo pela complexação com ácidos orgânicos. R. Bras. Ci. Solo, 16:209-215, 1992a.

MIYAZAWA, M.; PAVAN, M.A. \& BLOCH, M.F. Análise química de tecido vegetal. Londrina, Instituto Agronômico do Paraná, 1992b. 17p. (IAPAR Circular, 74)

MIYAZAWA, M.; PAVAN, M.A. \& FRANCHINI, J.C. Resíduo vegetal: influência na química dos solos ácidos. In: SIMPÓSIO SOBRE FERTILIDADE DO SOLO E NUTRIÇÃO DE PLANTAS NO SISTEMA PLANTIO DIRETO, 1., Ponta Grossa, 2000. Anais. Ponta Grossa, Associação dos Engenheiros Agrônomos dos Campos Gerais, 2000. p.82-94.

NOBLE, A.D. \& RANDALL, P.J. Ameliorating acid soils with organic materials: effects of amendments derived from coal on yield and composition of young wheat plants grown on an acid red podzol. Comm. Soil Sci. Plant Anal., 29:30233043, 1998.

OLIVEIRA, E.L.\& PAVAN, M.A. Control of soil acidity in no-tillage system for soybean production. Soil Till. Res., 38:47-57, 1996.

OLMOS,J J.I.L.\& CAMARGO, M.N. Ocorrência dealumíniotóxico nos solos do Brasil, sua caracterização e distribuição. Ci. Cult., 28:171-180, 1975.

PAVAN, M.A. Movimentação de calcário no solo através de técnicas de manejo de cobertura vegetal em pomares de macieira. R. Bras. Frut., 16:86-91, 1994

PAVAN, M.A. \& OLIVEIRA, E.L. Manejo da acidez do solo. Londrina, Instituto Agronômico do Paraná, 1997. 86p. (IAPAR Circular, 95)

PAVAN, M.A.; BINGHAM, F.T. \& PRATT, P.F. Redistribution of exchangeable calcium, magnesium, and aluminum following lime or gypsum applications to a brazilian oxisol. Soil Sci. Soc. Am. J., 48:33-38, 1984.

PAVAN, M.A.; BLOCH, M.F.; ZEMPULSKI, H.D.; MIYAZAWA, M. \& ZOCOLER, D.C. Manual de análise química do solo e controle de qualidade. Londrina, Instituto Agronômico do Paraná, 1992. 40p.(IAPAR. Circular, 76)

POHLMAN, A.A. \& MCCOLL, J.G. Soluble organics from forest litter and their role in metal dissolution. Soil Sci. Soc. Am. J., 52:265-271, 1988.

SHAINBERG, I.; SUMNER, M.E.; MILLER, W.P.; FARINA, M.P.W.; PAVAN, M.A. \& FEY, M.V. Use of gypsum on soils. A review. Adv. Soil Sci., 9:1-100, 1989.

SOPRANO, E. \& ALVAREZ, V.H. Nutrientes lixiviados de col unas de sol o tratadas com diferentes sais de cálcio. R. Bras. Ci. Solo, 13:25-29, 1989.

ZIGLIO, C.M.; MIYAZAWA, M. \& PAVAN, M.A. Formas orgânicas e inorgânicas de mobilização de cálcio no solo. Arq. Biol. Tecnol., 42:257-262, 1999. 